\title{
KARATERISTIK PASIEN APENDISITIS AKUT DI RUMAH SAKIT UMUM DAERAH DR. H. ABDUL MOELOEK PROVINSI LAMPUNG
}

\author{
Nopi Sani ${ }^{1}$, Arti Febriyani ${ }^{2}$, Yuni Fidia Hermina ${ }^{3}$ \\ ${ }^{1,2}$ Fakultas Kedokteran Universitas Malahayati \\ Email: artifebriyani16@gmail.com \\ ${ }^{3}$ Program Studi Kedokteran Fakultas Kedokteran Universitas Malahayati \\ Email: fidiayuni16@gmail.com
}

\section{ABSTRACT : ACUTE APPENDICITIS PATIENT CHARACTERISTICS AT HOSPITAL DR. H. ABDUL MOELOEK PROVINCE LAMPUNG}

Background: Appendicitis is an inflammation of the appendix vermiformis characterized by abdominal tenderness right lower quadrant, off the right lower quadrant pain, the pain shifts in the lower right quadrant, nausea, vomiting, anorexia, and fever. The incidence of appendicitis in Hospital Dr. H. Abdul Moeloek Bandar Lampung in 2017-2018 each month, including 10 common diseases.

Objective: The purpose of this study was To determine the characteristics of patients with acute appendicitis at Hospital Dr. H.Abdul Moeloek Bandar Lampung year 2017-2018

Methods: This research is a descriptive study using medical records. Samples in this research is all patient data appendicitis surgical inpatient unit and Rose, kutilang, kemuning Hospital Dr. H. Abdul Moeloek Bandar Lampung year 20172018 as many as 65 people. Data analysis using univariate analysis using the table in the presentation of data.

Research Result: The results of the study there were 65 patients who met the criteria for inclusion in the study. Of the 65 patients got acute appendicitis patient characteristics based age most $26-45(36,9 \%)$, gender women $(47,7 \%)$, men $(52,3 \%)$ is painful move in the right lower quadrant $(96,9 \%)$, anorexia $(50,8 \%)$, nausea and vomiting $(44,6 \%)$, pain in the right lower quadrant $(83,1 \%)$, just off the right lower quadrant pain $(64,6 \%)$, fever $(58,5 \%)$, leukocytes $\leq 10.000 \mathrm{~mm} 3(27,7 \%)$, leukocytes $\geq 10.000 \mathrm{~mm} 3 \quad(72,3 \%)$, neutrophil $\geq 75 \%$ (78,5\%), neutrophil $\leq 75 \%(21,5 \%)$

Keywords:Acute Appendicitis, RLQ, Characteristic.

\section{INTISARI: KARAKTERISTIK PASIEN APENDISITIS AKUT DI RUMAH SAKIT UMUM DAERAH DR. H. ABDUL MOELOEK PROVINSI LAMPUNG}

Latar Belakang: Apendisitis merupakan peradangan pada apendiks vermiformis yang ditandai dengan nyeri berpindah di kuadran kanan bawah, Anoreksi, mual muntah, nyeri tekan abdomen kuadran kanan bawah, nyeri lepas kuadran kanan bawah dan demam. Kejadian apendisitis di RSUD Dr. H. Abdul Moeloek Provinsi Lampung pada tahun 2017-2018 setiap bulannya termasuk 10 penyakit tersering.

\footnotetext{
Nopi Sani ${ }^{1}$, Arti Febriyani ${ }^{2}$, Yuni Fidia Hermina ${ }^{3}$

1,2Fakultas Kedokteran Universitas Malahayati. Email: artifebriyani16@gmail.com

${ }^{3}$ Fakultas Kedokteran Universitas Malahayati. Email: fidiayuni16@gmail.com
} 
Tujuan Penelitian: Untuk mengetahui hasil distribusi frekuensi Karakteristik pasien Apendisitis akut Di RSUD Dr. H.Abdul Moeloek Provinsi Lampung tahun 2017-2018.

Metode Penelitian: Jenis penelitian ini adalah deskriptif dengan pendekatan Cross-sectional menggunakan studi rekam medik. Sampel penelitian ini adalah seluruh data pasien apendisitis akut di ruang rawat inap bedah Mawar, Kutilang dan KemuningRSUD Dr. H. Abdul Moeloek Provinsi Lampung Tahun 2016-2017 sebanyak 65 orang. Analisis data menggunakan analisis univariat dengan menggunakan tabel dalam penyajian data.

Hasil Penelitian: Hasil penelitian terdapat 65 pasien yang memenuhi kriteria untuk dimasukkan dalam penelitian. Dari 65 pasien tersebut didapatkan karakteristik pasien apendisitis akut berdasarkan Usia paling banyak pada usia 26-45 tahun $(36,9 \%)$, jenis kelamin perempuan $(47,7 \%)$ laki-laki $(52,3 \%)$, nyeri berpindah di kuadran kanan bawah $(96,9 \%)$, anoreksia $(50,8 \%)$, mual dan muntah $(44,6 \%)$, nyeri kuadran kanan bawah $(83,1 \%)$, nyeri lepas kuadran kanan bawah $(64,6 \%)$, demam $(58,5 \%)$, peningkatan leukosit $\leq 10.000 \mathrm{~mm}^{3}(27,7 \%)$, peningkatan leukosit $\geq 10.000 \mathrm{~mm}^{3}(72,3 \%)$, peningkatan sel neutrofil $\geq 75 \%$ $(78,5 \%)$, peningkatan sel neutrofil $\leq 75 \%(21,5 \%)$.

Kata Kunci: Apendisitis akut, RLQ Karakteristik.

\section{PENDAHULUAN}

Apendisitis peradangan pada apendiks vermiformis yang dikenal oleh orang awam sebagai penyakit usus buntu yang di tandai dengan nyeri abdomen periumbilikal, mual, muntah, lokalisasi nyeri ke fosa iliaka kanan, nyeri tekan saat dilepas di sepanjang titik McBurney, nyeri tekan pelvis pada sisi kanan ketika pemeriksaan per rectal.(Thomas,2016).

$$
\text { Kejadian apendisitis }
$$

sebanyak 300.000 orang di Amerika serikat,tercatat sudah melakukan apendektomi, dengan perkiraan insiden kejadian 714\%.(Ferris,2017).Di Indonesia sebesar 596.132 orang dengan presentase 3,36\% pada tahun 2009, dan meningkat pada tahun 2010 menjadi 621.435 dengan presentase $3,53 \%$. Pada tahun 2013 sejumlah 5980 orang di Provinsi Lampung. (Depkes RI,2009). Di kota Bandar Lampung kasus appendisitis yakni sebesar 970 pasien (Dinkes Lampung, 2016). Dan pada tahun
2017-2018 d RSUD Dr. H. Abdul Moeloek sebanya 65 pasien dengan apendisitis akut.

Apendsitis jarang pada anak di bawah usia 1 tahun. (Thomas, 2016). Adanya peningkatan angka kejadian apendisitis dari usia 12 s/d 25 tahun. Sebaliknya terjadi pada usia $35 \mathrm{~s} / \mathrm{d} 45$ tahun ke usia 46 s/d 55 tahun. (Amalia, 2016).

Resiko jenis kelamin pada kejadian penyakit apendisitis terbanyak berjenis kelamin laki-laki dengan presentase $72,2 \%$ sedangkan berjenis kelamin perempuan hanya 27,8\%. (Indri,et al, 2014).

Apendisitis memiliki gejala kombinasi yang khas, yang terdiri dari : anoreksia, mual, muntah dan nyeri yang hebat di perut kanan bagian bawah. Nyeri bisa secara mendadak dimulai diperut sebelah atas atau di sekitar pusar, lalu timbul mual dan muntah. Setelah beberapa jam, rasa mual hilang dan nyeri berpindah ke perut kanan bagian bawah.( Dani \& Calista P. 2018). Penelitian nyeri tumpul saat

Nopi Sani ${ }^{1}$, Arti Febriyani ${ }^{2}$, Yuni Fidia Hermina ${ }^{3}$

1,2Fakultas Kedokteran Universitas Malahayati. Email: artifebriyani16@gmail.com

${ }^{3}$ Fakultas Kedokteran Universitas Malahayati. Email: fidiayuni16@gmail.com 
penekanan di lepas. (Sjamsuhidajat, De Jong, 2014).

pemeriksaan suhu tubuh dapat dijadikan penegak diagnosis apendisitis dimana suhu tubuh dibawah $<37^{\circ} \mathrm{C}$ pada pasien tanpa komplikasi, sedangkan pada pasien yang perforasi didapati demam tinggi dengan suhu tubuh diatas $38.3^{\circ} \mathrm{C}$. (Windy, 2016).

Meningkatnya jumlah sel darah putih antara $10.000 / \mathrm{mm}^{3}$ sampai $17.000 / \mathrm{mm}^{3}$ didapatkan pada $80 \%$ penderita apendisitis akut (Sherwood, l. 2014).

\section{METODE}

Penelitian ini bersifat kuantitatif, dengan menggunakan metode deskriptif observasional dengan desain cross sectional dimana peneliti mencari distribusi frekuensi dari karakteristik pasien apendisitis akut. Penlitian dilakukan di Rumah sakit umum Dr. H. Abdul moeloek provinsi Lampung. (Notoatmodjo,S. 2018).
Penelitian ini dilaksanakan pada bulan Februari 2020.

Populasi dalam penelitian ini adalah seluruh pasien di Rumah sakit umum Dr. H. Abdul Moeloek provinsi Lampung yang menderita apendisitis akut terdiri dari 65 orang. Sampel yang diambil dalam penelitian ini dilakukan dengan menggunakan teknik total sampling. (Sastroasmoro, 2011).

Untuk memperoleh informasi dari responden, peneliti menggunakan instrument penelitian berupa data sekunder yaitu data rekam medis dan sudah dilakukan uji plagiat sebesar $2 \%$.

Analisis data yang dilakukan pada penelitian ini meliputi analisis univariat. Dimana untuk mengetahui hasil distribusi frekuensi pasien apendisitis akut di RSUD Dr. $\mathrm{H}$. Abdul Moeloek Provinsi Lampung dengan menggunakan aplikasi SPSS 16.0. dan sudah dilakukan uji etik No./EC/KEP-UNMAL/II/2020.

HASIL

Analisis Univariat

1. Tabel Distribusi Frekuensi Pasien Berdasarkan Usia

\begin{tabular}{|c|c|c|c|}
\hline & Usia & \multirow{2}{*}{$\frac{\text { Frekuensi }}{1}$} & \multirow{2}{*}{$\frac{\text { Persentase (\%) }}{1.5}$} \\
\hline & $0-5$ tahun & & \\
\hline & 5-11 tahun & 21 & 32.3 \\
\hline & 12 - 25 tahun & 11 & 16.9 \\
\hline & $26-45$ tahun & 24 & 36.9 \\
\hline & $\begin{array}{l}46-65 \text { tahun } \\
>65 \text { tahun } \\
\end{array}$ & $\begin{array}{l}5 \\
3 \\
\end{array}$ & $\begin{array}{l}7.7 \\
4.6 \\
\end{array}$ \\
\hline & Total & 65 & 100 \\
\hline $\begin{array}{l}\text { Berdasarkan } \\
\text { menunjukkan } \\
\text { responden } \\
\text { distribusi pa } \\
\text { berdasaran u }\end{array}$ & 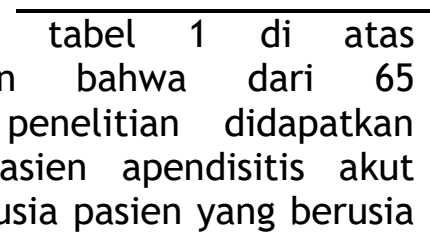 & $\begin{array}{l}0-5 \text { tahun } \\
(32,3 \%), 12-25 \\
\text { tahun(36,9\%), } \\
\text { dan pasien de } \\
\text { tahun dens }\end{array}$ & $\begin{array}{l}(1,5 \%), \quad 5-12 \text { tahun } \\
\text { tahun }(16,9 \%), 26-45 \\
46-65 \text { tahun }(7,7 \%), \\
\text { ggan usia lebih dari } 65 \\
\text { an presntasi( } 4,6 \%) .\end{array}$ \\
\hline
\end{tabular}

Tabel 2. Distribusi Frekuensi Pasien Berdasarkan Jenis Kelamin

Nopi Sani ${ }^{1}$, Arti Febriyani ${ }^{2}$, Yuni Fidia Hermina ${ }^{3}$

1,2Fakultas Kedokteran Universitas Malahayati. Email: artifebriyani16@gmail.com

${ }^{3}$ Fakultas Kedokteran Universitas Malahayati. Email: fidiayuni16@gmail.com 


\begin{tabular}{ccc}
\hline Jenis Kelamin & Frekuensi & Persentase (\%) \\
\hline Laki - laki & 34 & 52.3 \\
Perempuan & 31 & 47.7 \\
\hline Total & 65 & 100 \\
\hline
\end{tabular}

Berdasarkan tabel 2 di atas menunjukkan bahwa dari 65 responden penelitian didapatkan distribusi jenis kelamin pasien apendisitis akut terbanyak adalah
Laki - laki 34 responden $(52,3 \%)$, kemudian pada responden Perempuan sebanyak 31 responden $(47,7 \%)$.

Tabel 3. Karateristik Manifestasi Klinis Pasien Apendisitis Akut

1. Nyeri berpindah di kuadran kanan bawah

Tabel 3 Distribusi Frekuensi Pasien yang mengalami nyeri berpindah di kuadran kanan bawah

\begin{tabular}{ccc}
\hline $\begin{array}{c}\text { Nyeri berpindah di } \\
\text { kuadaran kanan bawah }\end{array}$ & Frekuensi & Persentase (\%) \\
\hline Ada & 63 & 96.9 \\
Tidak ada & 2 & 3.1 \\
\hline Total & 65 & $100 \%$ \\
\hline
\end{tabular}

Berdasarkan tabel 3 menunjukkan bahwa karakteristik berdasarkan manfestasi klinisnya untuk nyeri berpindah di kuadaran kanan bawah 63 responden $(96,9 \%)$ dan

yang tidak mengalami nyeri berpindah di kuadran kanan bawah sebanyak 2 pasien dengan presentasi sebesar $(3,1 \%)$.

\section{Anoreksia}

Tabel 4 Distribusi Frekuensi Pasien yang mengalami anoreksia

\begin{tabular}{ccc}
\hline Anoreksia & Frekuensi & Persentase (\%) \\
\hline Ada & 33 & 50,8 \\
Tidak ada & 32 & 49,2 \\
\hline Total & 65 & 100 \\
\hline $\begin{array}{c}\text { Berdasarkan tabel 4 } \\
\text { unjukkan bahwa 33 pasien }\end{array}$ & yang tidak mengalami \\
galami anoreksia dengan & anoreksia sebanyak 32 pasien \\
entasi $(50,8 \%)$ sedangkan & (49,2\%). presentasi sebesar
\end{tabular}

\section{Mual dan Muntah}

Nopi Sani ${ }^{1}$, Arti Febriyani ${ }^{2}$, Yuni Fidia Hermina ${ }^{3}$

1,2 Fakultas Kedokteran Universitas Malahayati. Email: artifebriyani16@gmail.com

${ }^{3}$ Fakultas Kedokteran Universitas Malahayati. Email: fidiayuni16@gmail.com 
Tabel 5 Distribusi yang mengalami mual dan muntah

\begin{tabular}{ccc}
\hline Mual dan Muntah & Frekuensi & Persentase (\%) \\
\hline Ada & 29 & 44.6 \\
Tidak ada & 36 & 55.4 \\
\hline Total & 65 & 100 \\
\hline $\begin{array}{c}\text { Berdasarkan tabel 5 } \\
\text { unjukkan bahwa 29 pasien }\end{array}$ & \multicolumn{2}{c}{ dan musien dengan sebanyak 36 presentasi } \\
sebesar (55,4\%).
\end{tabular}

yang tidak mengalami mual

Tabel 4. Karateristik Pemeriksaan Fisik

1. Nyeri tekan di kuadran kanan bawah

Tabel 4 Distribusi Frekuensi Nyeri Tekan di kuadran kanan bawah

Nyeri Tekan (+) Kuadran Kanan Bawah

Frekuensi

Persentase (\%)

\begin{tabular}{ccc}
\hline Ada & 54 & 83.1 \\
Tidak ada & 11 & 16.9 \\
\hline Total & 65 & 100 \\
\hline
\end{tabular}

Berdasarkan tabel 4.1 menunjukkan bahwa dengan presentasi sebesar karakteristik berdasarkan $(16,9 \%) \quad$ yang tidak Pemeriksaan Fisik 54 pasien mengeluhkan nyeri tekan di kuadran kanan bawah.

dengan presentasi $(83,1 \%)$, sisanya hanya 11 pasien

2. Nyeri lepas tekan di kuadran kanan bawah

Tabel 6 Distribusi Frekuensi Pasien yang mengalami Nyeri Lepas tekan di Kuadran Kanan Bawah

\begin{tabular}{ccc}
\hline $\begin{array}{c}\text { Nyeri lepas tekan di } \\
\text { kuadran kanan bawah }\end{array}$ & Frekuensi & Persentase (\%) \\
\hline Ada & 42 & 64.6 \\
Tidak ada & 23 & 35.4 \\
\hline Total & 65 & 100 \\
\hline Berdasarkan tabel 6 & sisanya 23 pasien apendisitis \\
unjukkan bahwa 42 pasien & akut dengan presentasi \\
mengeluhkan adanya & sebesar (35,4\%) tidak \\
lepas tekan pada & mengeluhkan Nyeri lepas \\
tekan di kuadran kanan & bawah.
\end{tabular}

sebesar $(64,6 \%)$, sedangkan

3. Peningkatan suhu $\left(\geq 37,3^{\circ} \mathrm{C}\right)$

Nopi Sani ${ }^{1}$, Arti Febriyani ${ }^{2}$, Yuni Fidia Hermina ${ }^{3}$

1,2Fakultas Kedokteran Universitas Malahayati. Email: artifebriyani16@gmail.com

${ }^{3}$ Fakultas Kedokteran Universitas Malahayati. Email: fidiayuni16@gmail.com 
Tabel 7 Distribusi Frekuensi Peningkatan Suhu $\left(\geq 37,3^{\circ} \mathrm{C}\right)$

\begin{tabular}{|c|c|c|}
\hline $\begin{array}{c}\text { Peningkatan } \\
\text { Suhu }\left(\geq 37,3^{\circ} \mathrm{C}\right)\end{array}$ & Frekuensi & Persentase (\%) \\
\hline Ada & 38 & 58.5 \\
\hline Tidak ada & 27 & 41.5 \\
\hline Total & 65 & 100 \\
\hline $\begin{array}{lcr}\text { Pada } & \text { tabel } 7 & \text { dari } 65 \\
\text { en } & \text { apendisitis } & \text { akut } \\
\text { apat } 27 \text { pasien } & \text { dengan } \\
\text { entasi } & \text { sebesar } & (41,5 \%)\end{array}$ & \multicolumn{2}{|c|}{$\begin{array}{l}\text { suhu } \geq 37,3^{\circ} \mathrm{C} \text {, sedangkan } 38 \\
\text { pasien dengan presentasi } \\
\text { sebesar }(58,5 \%) \text { mengalami } \\
\text { peningkatan suhu tubuh. }\end{array}$} \\
\hline
\end{tabular}

tidak mengalami peningkatan

Tabel 8. Karateristik Pemeriksaan laboratorium

1. Peningkatan leukosit $\geq 10.000 \mathrm{~mm}^{3}$

Tabel 8 Distribusi Frekuensi Peningkatan leukosit $\geq 10.000 \mathrm{~mm}^{3}$

\begin{tabular}{|c|c|c|}
\hline Leukosit $\geq 10.000 \mathrm{~mm}^{3}$ & Frekuensi & Persentase (\%) \\
\hline$\leq 10.000 \mathrm{~mm}^{3}$ & 17 & 26.2 \\
\hline$\geq 10.000 \mathrm{~mm}^{3}$ & 48 & 73.8 \\
\hline Total & 65 & 100 \\
\hline $\begin{array}{lr}\text { asarkan } & \text { tabel } \\
\text { n bahwa } & \text { karakteristik } \\
\text { laboratorium } & \text { Leukosit } \\
\mathrm{mm}^{3} \quad 48 & \text { responden }\end{array}$ & $\begin{array}{l}\text { darah } \geq 10 \\
\text { leukosit } \\
\text { sebanyak } \\
\text { presentasi ( }\end{array}$ & $\begin{array}{l}\mathrm{mm}^{3} \text {. Dan dengan } \\
\leq 10.000 \quad \mathrm{~mm}^{3} \\
\text { pasien dengan } \\
\%) \text {. }\end{array}$ \\
\hline
\end{tabular}

menunjukkan bahwa karakteristik leukosit darah $\leq 10.000 \mathrm{~mm}^{3}$ Pemeriksaanlaboratorium Leukosit sebanyak 17 pasien dengan $\geq 10.000 \mathrm{~mm}^{3} \quad 48$ responden presentasi $(26,2 \%)$.

presentasi $(73,8 \%)$ dengan leukosit

2. Peningkatan sel neutrofil $\geq 75 \%$

Tabel 9 Distribusi Frekuensi Peningkatan sel neutrofil $\geq 75 \%$

Sel neutrofil Frekuensi Persentase (\%)

\begin{tabular}{|c|c|c|}
\hline$\leq 75 \%$ & 14 & 21,5 \\
\hline$\geq 75 \%$ & 51 & 78,5 \\
\hline Total & 65 & 100 \\
\hline $\begin{array}{lr}\text { Berdasarkan } & \text { tabel } 9 \\
\text { unjukkan bahw } & 51 \text { pasien } \\
\text { an presentasi } & \text { sebesar } \\
5 \% \text { pada pemeriksaan } \\
\text { ratorium } & \text { ditemukan }\end{array}$ & $\begin{array}{l}\geq 75 \% \\
\text { sebanyak } \\
\text { presentasi } \\
\text { mengalam } \\
\text { neutrofil }\end{array}$ & 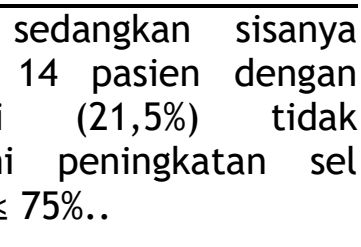 \\
\hline
\end{tabular}

peningkatan sel neutrofil

\footnotetext{
Nopi Sani ${ }^{1}$, Arti Febriyani ${ }^{2}$, Yuni Fidia Hermina ${ }^{3}$

1,2Fakultas Kedokteran Universitas Malahayati. Email: artifebriyani16@gmail.com

${ }^{3}$ Fakultas Kedokteran Universitas Malahayati. Email: fidiayuni16@gmail.com
} 


\section{PEMBAHASAN}

Pada usia pasien apendisitis akut 25-44 tahun menjadi usia terbanyak pada penderita apendisitis akut sebanyak 24 pasien dengan presentasi sebesar $(36,9 \%)$, dan menurun pada usa $>65$ tahun sebanyak3 pasien dengan presentasi sebesar $(4,6 \%)$ Hasil penelitian ini sejalan dengan penelitian yang dilakukan oleh Thomas (2016) di RSUP Prof. Dr. R. D. Kandou Manado.

Distribusi frekuensi pasien apendisitis akut berdasarkan jenis kelamin dari 65 pasien berjenis kelamin laki-laki sebanyak 34 pasien dengan presentasi sebesar (52,3\%) hal ini sejalan dengan penelitian yang dilakukan olehdilakukan Amalia (2016) pada pasien apendisitis akut di RSU Kota Tangerang Selatan.

Distribusi frekuensi pasien apendisitis akut berdasarkan keluhan nyeri berpindah di kuadran kanan bawah sebanyak 65 pasien apendisitis akut terdapat 63 pasien mengalami nyeri berpindah di kuadran kanan bawah dengan presentasi sebesar $(96,9 \%)$ Hasil penelitian ini sejalan dengan penelitian yang di lakukan oleh Fransisca (2019) tentang karakteristik pasien dengan gambaran histopatologi apendisitis berdasarkan di RSUP Sanglah Denpasar di dapatkan sebanyak 723 pasien apendisitis akut yang mengeluhkan nyeri berpindah di kuadran kanan bawah sebanyak 628 pasien dengan presentasi sebesar $(86,9 \%)$.

pasien apendisitis akut yang merasakan Anoreksia sebanyak 33 pasien dengan presentasi sebesar $(50,8 \%)$ Hasil penelitian ini sejalan dengan penelitian yang di lakukan oleh Zuriati (2016) tentang karakteristik penderita apendisitis akut di RSUD Palembang Bari di dapatkan sebanyak 48 pasien apendisitis akut yang mengeluhkan mengalami Anoreksia sebanyak 22 pasien mengalami anoreksia dengan presentasi sebesar $(45,8 \%)$ Hasil penelitian ini sejalan dengan penelitian yang di lakukan oleh Zuriati (2016) tentang karakteristik penderita apendisitis akut di RSUD Palembang Bari di dapatkan sebanyak 48 pasien apendisitis akut yang mengeluhkan mengalami Anoreksia sebanyak 22 pasien mengalami anoreksia dengan presentasi sebesar $(45,8 \%)$. pasien apendisitis akut terdapat 42 pasien yang mengeluhkan mual dan muntah dengan presentasi sebesar $(64,6 \%)$, Hasil penelitian ini sejalan dengan penelitian yang di lakukan oleh Zuriati (2016) karakteristik penderita apendisitis akut di RSUD Palembang Bari di dapatkan sebanyak 48 pasien apendisitis akut yang mengeluhkan mengalami mual dan muntah sebanyak 40 pasien dengan presentasi sebesar $(83,3 \%)$.

65 pasien yang mengeluhkan adanya nyeri tekan pada abdomen kuadran kanan bawah sebanyak 54 pasien dengan presentasi sebesar $(83,1 \%)$, Hasil penelitian ini sejalan dengan penelitian yang di lakukan oleh Zuriati (2016) tentang karakteristik penderita apendisitis akut di RSUD Palembang Bari di dapatkan sebanyak 48 pasien apendisitis akut yang mengeluhkanadanya nyeri tekan pada abdomen kuadran kanan bawah sebanyak 47 pasien dengan presentasi sebesar (100\%).

Pasien apendisitis akut terdapat 42 pasien yang mengeluhkan adanya nyeri lepas tekan pada abdomen kuadran kanan bawah dengan presentasi sebesar $(64,6 \%)$, Hasil penelitian ini tidak

Nopi Sani ${ }^{1}$, Arti Febriyani ${ }^{2}$, Yuni Fidia Hermina ${ }^{3}$

1,2Fakultas Kedokteran Universitas Malahayati. Email: artifebriyani16@gmail.com

${ }^{3}$ Fakultas Kedokteran Universitas Malahayati. Email: fidiayuni16@gmail.com 
sesuai dengan penelitian yang di lakukan oleh Zuriati (2016) tentang karakteristik penderita apendisitis akut di RSUD Palembang Bari di dapatkan sebanyak 48 pasien apendisitis akut yang mengeluhkan adanya nyeri lepas tekan pada abdomen kuadran kanan bawah sebanyak 48 pasien dengan presentasi sebesar (100\%).

Pasien apendisitis akut terdapat 27 pasien yang tidak mengeluhkan adanya peningkatan suhu $\left(\geq 37,3^{\circ} \mathrm{C}\right)$ dengan presentasi sebesar $(41,5 \%)$ Hasil penelitian ini tidak sesuai dengan penelitian yang di lakukan oleh windy (2016) tentang perbandingan antara suhu tubuh, kadar leukosit, dan Platelet Distribution Width (PDW) pada apendisitis akut dan apendisitis perforasi di Rumah Sakit Umum Anutapura Palu didapatkan sebanyak 52 pasienmengala peningatan suhu.

Pasien dengan leukosit $\geq 10.000 \mathrm{~mm}^{3}$ sebanyak 47 pasien dengan presentasi sebesar $(72,3 \%)$. Hasil penelitian ini sejalan dengan penelitian yang di lakukan oleh Windy (2016) tentang perbandingan antara suhu tubuh, kadar leukosit, dan Platelet Distribution Width (PDW) pada apendisitis akut dan apendisitis perforasi di Rumah Sakit Umum Anutapura Palu di dapatkan sebanyak 52 pasien.

peningkatan sel neutrofil $\geq 75 \%$ sebanyak 65 pasien terdapat 51 pasien dengan presentasi sebesar $(78,5 \%)$ Hasil penelitian ini sejalan dengan penelitian yang di lakukan oleh Zuriati (2016) tentang karakteristik penderita apendisitis akut di RSUD Palembang Bari di dapatkan sebanyak 48 pasien.

\section{KESIMPULAN}

Berdasarkan hasil penelitian, analisis data, dan pembahasan penelitian tentang Karateristik Pasien Apendisitis Akut Di Rumah Sakit Umum Dr. H. Abdul Moeloek Provinsi Lampung Tahun 20172018.dapat diambil kesimpulan sebagai berikut:

1. Karakteristik pasien berdasarkan usia pada rentan usia 25-44 tahun yang menjadikan puncak usia terbanyak penderita apendisitis akut dan pasien yang berusia 45-64 tahun sebanyak 5 orang dengan presentasi sebesar $(7,7 \%)$ menjadikan fase penuruanan usia penderita apendisitis akut.

2. Karakteristik pasien berdasarkan jenis kelamin pasien apendisitis akut terbanyak pada Laki-laki yaitu 34 pasien dengan presentasi sebesar $(52,3 \%)$.

3. Karakteristik pasien berdasarkan manifestasi klinisnya nyeri berpindah di kuadran kanan bawah( $96,9 \%)$, mual dan muntah (64,6\%), Anoreksia (50,8\%).

4. Karakteristik pasien apendisitisakut berdasarkan pemeriksaan fisik nyeri tekan di kuadran kanan bawah $(83,1 \%)$,nyeri tekan lepas di kuadran kanan bawah $(64,6 \%)$, peningkatan suhu $\geq 37,3^{\circ} \mathrm{C}(58,5 \%)$.

5. Karakteristik pasien apendisitisakut berdasarkan hasil pemeriksaan laboratorium leukosit $\geq 10.000 \mathrm{~mm}^{3}$ (72,3\%), sel neutrofil $\geq 75 \%(78,5 \%)$.

\section{SARAN}

Bagi peneliti selanjutnya perlu dilakukan penelitian lebih lanjut untuk mengetahuiKarakteristik pasien apendisitisakut dan juga mengambil jumlah sampel penelitian yang lebih

Nopi Sani ${ }^{1}$, Arti Febriyani ${ }^{2}$, Yuni Fidia Hermina ${ }^{3}$

${ }^{1,2}$ Fakultas Kedokteran Universitas Malahayati. Email: artifebriyani16@gmail.com

${ }^{3}$ Fakultas Kedokteran Universitas Malahayati. Email: fidiayuni16@gmail.com 
besar agar hasil penelitian lebih representatif.

\section{UCAPAN TERIMA KASIH}

Peneliti mengucapkan terima kasih kepada Allah SWT yang telah memberikan rahmat dan pertolongannya sehingga penelitian ini dapat berjalan dengan lancar. Peneliti juga mengucapkan terima kasih kepada semua pihak yang berperan dalam pelaksanaan penelitian ini, terutama kepada seluruh anggota dan pengurus diRumah Sakit Umum Dr. H. Abdul Moeloek Provinsi Lampung.

\section{DAFTAR PUSTAKA}

Amalia, Iftina. (2016). Gambaran Sosio Demografi dan Gejala Apendisitis Akut di RSU Kota Tanggerang Selatan. Skripsi.Program Studi Kedokteran dan Profesi dokter Universitas Islam Negri Jakarta. Jakarta.

Craig, Sandy. (2014). Appendicitis. http:/ / emedicine.medscape.c om/artiOctober 12th. 2014. Update $21^{\text {st }}$ Desember, 2017.

\section{Dani \& Calista P. (2018). Karakteristik pasien apendisitis akut di Rumah Sakit Immanuel Bandung periode 1 Januari 2013-30 Juni 2013. Repository Maranatha. Tersedia di: http://repository.maranatha. edu/id/eprint/12568. \\ Bandung. 14 Juli 2018.}

$\begin{array}{ccr}\text { Departemen } & \text { Kesehatan } & \text { Repulik } \\ \text { Indonesia. } & \text { (2016). } & \text { Profil } \\ \text { Kesehatan } & \text { Indonesia } & 2009 . \\ \text { Indonesia: } & \text { Depkes } & \text { Republik } \\ \text { Indonesia. } & & \end{array}$

Departemen Bedah Universitas Gadjah Mada. 2010. Apendik. Tersedia Dari http://Www.Badahugm.Net/T ag/Appendix. 20 Januari 2018.

Ferris M, et. al. 2017. The Global Incidence of Appendicitis. A Systematic Review of Population-based Studies.

Fransisca, C. 2019. Karakteristik Pasien Dengan Gambaran Histopatologi Apendisitis Di Rsup Sanglah Denpasar Tahun 2015 - 2017. jurnal medika udayana .

Guyton, A.C., \& Hall, J.E. (2016). Textbook of Medical Physiology. (11 ${ }^{\text {th }}$ ed). Jakarta:Buku Kedokteran EGC.

Hungu. (2007). The influence of sex and age on appendicitis in children and young adults. journal Gut , 80-84.

Indri U. (2014). Hubungan Antara Nyeri, Kecemasan Dan Lingkungan Dengan Kualitas Tidur Pada Pasien Post Operasi Apendisitis: Program Studi Ilmu Keperawatan, jurnal Universitas Riau.

Marisa. (2013). Batas angka leukosit antara appendicitis akut dan appendicitis perforasi di rumah sakit umum daerah tugurejo semarang selama Januari 2009 - Juli 2011. Jurnal Kedokteran Muhammadiyah. http://jurnal.unimus.ac.id/in dex.php/kedokteran/article/v iew/739.

\footnotetext{
Nopi Sani ${ }^{1}$, Arti Febriyani ${ }^{2}$, Yuni Fidia Hermina ${ }^{3}$

1,2Fakultas Kedokteran Universitas Malahayati. Email: artifebriyani16@gmail.com

${ }^{3}$ Fakultas Kedokteran Universitas Malahayati. Email: fidiayuni16@gmail.com
} 
Notoatmodjo,S. (2018). Metodologi Penelitian Kesehatan. Jakarta: RinekaCipta.

Sastroasmoro,S., Ismael., S. (2014). Dasar-dasar Metodelogi Penelitian Klinis. $\left(5^{\text {th }}\right.$ ed). Jakarta: Sagung Seto. Hal. 130-376.

Sherwood, l. (2014). Fisiologi

Manusia Dari sel ke sistem.

$\left(8^{\text {th }}\right.$ ed). Jakarta: EGC.

Sjamsuhidayat, R\& W. d. Jong, Penyunt..Hafid, A., \&Syukur, A. (2017). Buku Ajar IlmuBedah. Jakarta: Penerbit Buku Kedokteran EGC. P. 776781.

Sugiyono. (2016). Metode Penelitian Pendidikan Pendekatan Kuantitatif, kualitatif, dan R\&D. Bandung: Alfabeta.

Thomas, G. A. (2016). Angka kejadian apendisitis di RSUP Prof. Dr. R. D. Kandou Manado. jurnal e-clinic , 231232.

Windy, C.S . (2016). Perbandingan Antara Suhu Tubuh, Kadar Leukosit, DanPlatelet Distribution Width (Pdw) Pada Apendisitis Akut Dan Apendisitis Perforasi Di Rumah Sakit Umum Anutapura Palu Tahun 2014. jurnal kesehatan tandulako , 25-27.

Zuriati, R. (2016). Karakteristik penderita Apendisitis Akut di RSUD Palembang Bari Periode1 Januari 2011-31 Desember 2014. Skripsi. Fakultas Kedokteran Univeritas MuhammadiyahPalembang. Palembang. 